\title{
Nitric Oxide Gas Sensors Using Multilayered Thin Film with Interspaces
}

\author{
Akihiro Shimizu, Tsubasa Morita, Tomiharu Yamaguchi, and Kazuhiro Hara \\ Graduate School of Engineering, Tokyo Denki University, \\ 5 Senju-Asahi-cho, Adachi-ku, Tokyo 120-8551, Japan
}

(Received December 4, 2017; accepted April 10, 2018)

Keywords: $\mathrm{NO}$ gas sensor, $\mathrm{WO}_{3}$ thin film, Ag catalyst, interspace, multiple-layered configuration

Nitric oxide (NO) is an air pollutant known to adversely affect the environment, humans, and other living organisms. Low-level NO gas is also created by human bodies and emitted as a component of exhaled breath and skin gas under some health conditions. Therefore, there is a strong demand for the monitoring of $\mathrm{NO}$ gas concentration. In this paper, we present novel NO gas sensors that have been developed using multilayered $\mathrm{WO}_{3}$-based thin films with interspaces. $\mathrm{Ag}$ doping into a $\mathrm{WO}_{3}$ thin film is effective in increasing the sensitivity to NO. Multilayered thin-film sensors with interspaces successfully enhance both sensitivity and selectivity to NO. The developed sensor with quadruple-layered sensing films can detect as low as $0.5 \mathrm{ppm}$ NO gas with good selectivity at an operating temperature of $290{ }^{\circ} \mathrm{C}$. The response and recovery times are 81 and $138 \mathrm{~s}$, respectively, for the double-layered sensor, while its sensitivity is lower than that of the quadruple-layered sensor. Thus, the sensors are promising as a portable and inexpensive NO sensing device in various application fields such as environmental monitoring and health diagnosis.

\section{Introduction}

Nitric oxide (NO) is a harmful gas, which is generated by internal combustion engines, thermal power plants, industrial furnaces, and boilers and emitted as a component of exhaust gas. ${ }^{(1)}$ It reacts with oxygen and moisture in the air to form $\mathrm{HNO}_{2}$, which falls as acid rain. It causes photochemical smog and destroys the ozone layer. ${ }^{(2)}$ In addition, it is an important cellular signaling molecule in humans and animals involved in many physiological and pathological processes. Low-level NO gas is also created by human bodies and emitted as a component of exhaled breath and skin gas under some health conditions. It is known that the exhaled air from patients suffering from asthma includes higher levels of NO. Therefore, the monitoring of NO gas concentration has attracted attention in various fields.

The concentration of $\mathrm{NO}$ in air can be determined by a chemiluminescent technique. The Saltzman method using the Griess-Saltzman reaction is also widely adopted. However, both methods require large and expensive equipment. Thus, there is a need for inexpensive

*Corresponding author: e-mail: t-yama@mail.dendai.ac.jp

http://dx.doi.org/10.18494/SAM.2018.1836 
and portable sensors in various fields. Although semiconductor gas sensors as well as electrochemical sensors have been developed to determine the concentration of $\mathrm{NO}^{(3-7)}$ in general, they are poor at distinguishing $\mathrm{NO}$ from $\mathrm{NO}_{2}$.

In this paper, we present novel semiconductor thin-film $\mathrm{NO}$ gas sensors using a $\mathrm{WO}_{3}$ based sensing film and a $\mathrm{Ag}$ catalyst with a multilayer configuration and interspaces between the sensing films. The $\mathrm{WO}_{3}$-based material is sensitive to $\mathrm{NO}_{x}{ }^{\left({ }^{8-12}\right)} \mathrm{Ag}$ doping into the $\mathrm{WO}_{3}$ thin film is effective in increasing the sensitivity to $\mathrm{NO}^{(13,14)}$ A multilayered thin film with interspaces ${ }^{(15)}$ successfully enhances both sensitivity and selectivity to NO.

\section{Sensor Configuration and Materials}

Two types of sensors have been developed and examined. The first one is a metal-oxide thin-film sensor without interspaces. The second one is a metal-oxide multilayered sensor with interspaces. The former has been fabricated to find effective materials and catalysts for detecting NO. The latter has been exploited to investigate the best configuration for a multilayered thin-film sensor with interspaces.

\subsection{Thin-film sensors without interspaces}

Figure 1 shows the configuration of a metal-oxide thin-film gas sensor. This sensor was also used as a reference sample. The substrate used was alumina and its dimension was $10 \times 10 \times$ $1 \mathrm{~mm}^{3}$. The sensing film has a double-layered structure without interspaces. The material for the first layer of the sensing film was $\mathrm{Fe}_{2} \mathrm{O}_{3}+\mathrm{TiO}_{2}(5 \mathrm{~mol} \%)+\mathrm{MgO}(4 \mathrm{~mol} \%) ; \mathrm{TiO}_{2}$ was doped to increase the electron concentration in the $\mathrm{Fe}_{2} \mathrm{O}_{3}$ film, decreasing the sensor resistance while $\mathrm{MgO}$ was added to improve the stability of the film. The material for the second layer was $\mathrm{WO}_{3}+\mathrm{Ag} ; \mathrm{Ag}$ was doped to the $\mathrm{WO}_{3}$-based film to increase the sensitivity to NO. Four kinds of sensors were fabricated with different Ag doping amounts of 2, 1, 0.5, and $0 \mathrm{wt} \%$ (nondoped). The active area of the sensing film was about $1 \times 1 \mathrm{~mm}^{2}$ and the thickness of both the first and second layers was $100 \mathrm{~nm}$.

In general, $\mathrm{WO}_{3}$-based films are more sensitive to $\mathrm{NO}$ than $\mathrm{Fe}_{2} \mathrm{O}_{3}$-based ones. However, $\mathrm{WO}_{3}$-based films tend to often generate cracks during operation and thus the resistance of the films gradually increases with time. The bandgap of the $\mathrm{Fe}_{2} \mathrm{O}_{3}$-based film (ca. $2.3 \mathrm{eV}$ ) is

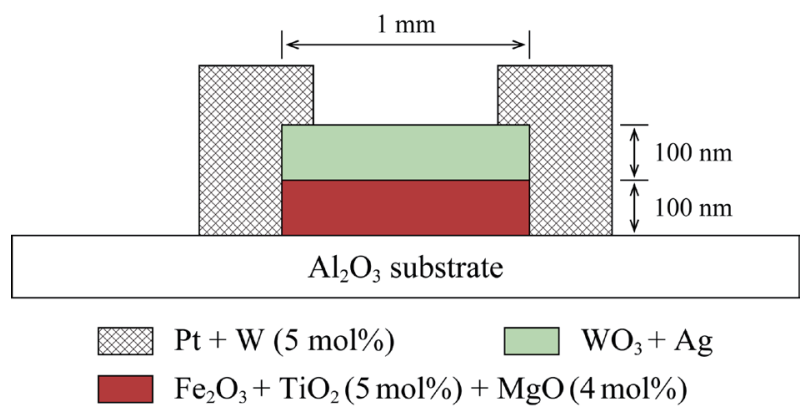

Fig. 1. (Color online) Cross-sectional view of a thin-film gas sensor without interspaces. 
smaller than that of the $\mathrm{WO}_{3}$-based one (ca. $2.8 \mathrm{eV}$ ). By using a double-layered configuration, most electrons flow in the $\mathrm{Fe}_{2} \mathrm{O}_{3}$-based film with a smaller bandgap. ${ }^{(16)}$ The $\mathrm{Fe}_{2} \mathrm{O}_{3}$-based film seldom generates cracks, while possible cracks in the $\mathrm{WO}_{3}$-based film do not have an adverse effect on the sensor resistance. Moreover, the $\alpha$-type $\mathrm{Fe}_{2} \mathrm{O}_{3}$-based film has the same crystalline structure of corundum type as that of the alumina substrate. Hence, the adhesion of the $\mathrm{Fe}_{2} \mathrm{O}_{3}$ based film to the alumina substrate is good. In addition, the thermal expansion coefficient of the $\mathrm{Fe}_{2} \mathrm{O}_{3}$-based film is close to that of the alumina substrate. Thus, the internal stress associated with temperature rise inside the $\mathrm{Fe}_{2} \mathrm{O}_{3}$-based film is small, reducing the generation of cracks.

The material for the electrode was $\mathrm{Pt}+\mathrm{W}(5 \mathrm{~mol} \%)$; W was doped to enhance the durability of the Pt film. The thickness of the electrode was $200 \mathrm{~nm}$. All the films were deposited by RF sputtering. The sputtering conditions are summarized in Table 1. All the target materials were of analytical grade. Photolithography was used to define the sensor and electrode geometries. The films were thermally treated at $600{ }^{\circ} \mathrm{C}$ for $5 \mathrm{~h}$ in air to allow for the recovery from various defects and the stabilization of the crystal structure.

\subsection{Multilayered sensors with interspaces}

Figure 2 shows the configuration of a multilayered metal-oxide thin-film gas sensor with interspaces. The substrate was alumina and its dimension was $10 \times 10 \times 1 \mathrm{~mm}^{3}$. The sensing

Table 1

Sputtering condition.

\begin{tabular}{|c|c|c|c|c|}
\hline & $\mathrm{Fe}_{2} \mathrm{O}_{3}+\mathrm{TiO}_{2}+\mathrm{MgO}$ & $\mathrm{WO}_{3}+\mathrm{Ag}$ & $\mathrm{SiO}_{2}, \mathrm{SiO}_{2}+\mathrm{Al}_{2} \mathrm{O}_{3}$ & $\mathrm{Pt}+\mathrm{W}$ \\
\hline Sputtering target & $\begin{array}{c}\text { Mixed powder of } \\
\mathrm{Fe}_{2} \mathrm{O}_{3}(91 \mathrm{~mol} \%), \mathrm{TiO}_{2}(5 \mathrm{~mol} \%), \\
\text { and } \mathrm{MgO}(4 \mathrm{~mol} \%)\end{array}$ & $\begin{array}{l}\text { Mixed powder of } \\
\mathrm{WO}_{3} \text { and } \mathrm{Ag}\end{array}$ & $\begin{array}{l}\text { Small pieces of } \mathrm{Al}_{2} \mathrm{O}_{3} \\
\text { on a disc of } \mathrm{SiO}_{2}\end{array}$ & $\begin{array}{c}\text { Small sheets of } \mathrm{W} \\
\text { on a sheet of } \mathrm{Pt}\end{array}$ \\
\hline Sputtering atmosphere & $\operatorname{Ar}(80 \%)$ and $\mathrm{O}_{2}(20 \%)$ & $\operatorname{Ar}(80 \%)$ and $\mathrm{O}_{2}(20 \%)$ & $\operatorname{Ar}(80 \%)$ and $\mathrm{O}_{2}(20 \%)$ & $\operatorname{Ar}(100 \%)$ \\
\hline Power density & $12 \mathrm{~W} / \mathrm{cm}^{2}$ & $12 \mathrm{~W} / \mathrm{cm}^{2}$ & $12 \mathrm{~W} / \mathrm{cm}^{2}$ & $12 \mathrm{~W} / \mathrm{cm}^{2}$ \\
\hline
\end{tabular}

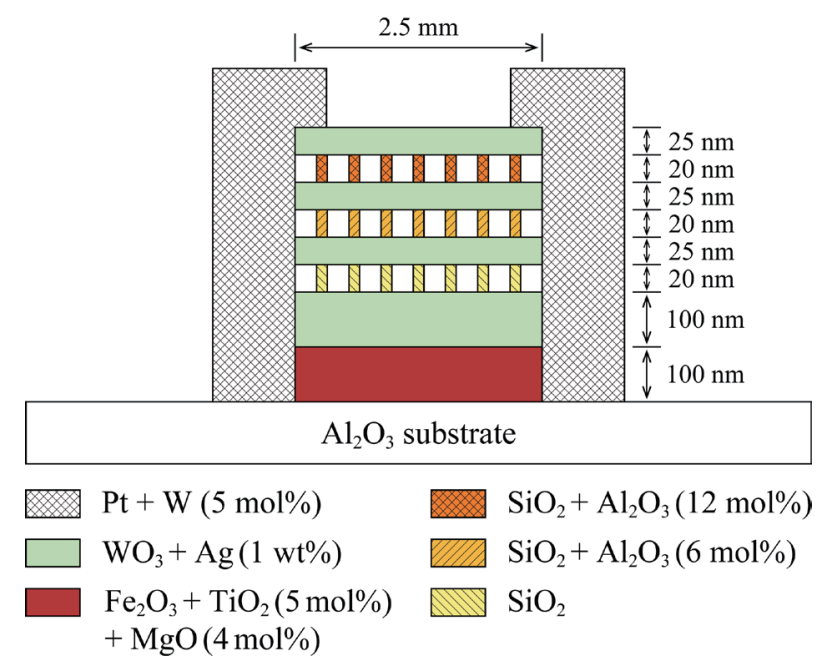

Fig. 2. (Color online) Cross-sectional view of a triple-layered thin-film gas sensor with interspaces. 
film has a quadruple-layered structure with interspaces. The first and second layers of the sensing film are $\mathrm{Fe}_{2} \mathrm{O}_{3}+\mathrm{TiO}_{2}(5 \mathrm{~mol} \%)+\mathrm{MgO}(4 \mathrm{~mol} \%)$ and $\mathrm{WO}_{3}+\mathrm{Ag}$, respectively. The third to eighth layers are $\mathrm{SiO}_{2}, \mathrm{WO}_{3}+\mathrm{Ag}(1 \mathrm{wt} \%), \mathrm{SiO}_{2}+\mathrm{Al}_{2} \mathrm{O}_{3}(6 \mathrm{~mol} \%), \mathrm{WO}_{3}+\mathrm{Ag}(1$ $\mathrm{wt} \%), \mathrm{SiO}_{2}+\mathrm{Al}_{2} \mathrm{O}_{3}(12 \mathrm{~mol} \%)$, and $\mathrm{WO}_{3}+\mathrm{Ag}(1 \mathrm{wt} \%)$, respectively. The thicknesses of the third to eighth layers are 20,25, 20,25, 20, and $25 \mathrm{~nm}$, respectively. The films were thermally treated at $600{ }^{\circ} \mathrm{C}$ for $5 \mathrm{~h}$ in air. The morphology of the $\mathrm{WO}_{3}$-based films changed after this heat treatment from dense to porous, which enabled the sacrificial etching of $\mathrm{SiO}_{2}$-based films through microscopic pores of the $\mathrm{WO}_{3}$-based films. ${ }^{(15)}$ Then $\mathrm{SiO}_{2}+\mathrm{Al}_{2} \mathrm{O}_{3}(12 \mathrm{~mol} \%), \mathrm{SiO}_{2}+$ $\mathrm{Al}_{2} \mathrm{O}_{3}\left(6 \mathrm{~mol} \%\right.$ ), and $\mathrm{SiO}_{2}$ layers were partly dissolved with $1 \%$ fluoric acid, leaving pillars that supported the upper and lower $\mathrm{WO}_{3}$-based films.

In the etching process, fluoric acid first penetrates through the top sensing film, next dissolves the upper sacrificial layer, then penetrates through the upper middle sensing film, next dissolves the middle sacrificial layer, then penetrates through the lower middle sensing film, and finally dissolves the lower sacrificial layer. In this process, the dissolution rates of the upper and middle sacrificial layers made of $\mathrm{SiO}_{2}+\mathrm{Al}_{2} \mathrm{O}_{3}(12 \mathrm{~mol} \%)$ and $\mathrm{SiO}_{2}+\mathrm{Al}_{2} \mathrm{O}_{3}(6 \mathrm{~mol} \%)$ were low and thus supporting pillars were sufficiently thick even after a prolonged etching process. The dissolution rate of the lower sacrificial layer made of $\mathrm{SiO}_{2}$ was high and thus enough interspaces were formed. The measured dissolution rates were 4.8, 3.0, and $3.6 \mathrm{~nm} / \mathrm{min}$ for $\mathrm{SiO}_{2}, \mathrm{SiO}_{2}+\mathrm{Al}_{2} \mathrm{O}_{3}(6 \mathrm{~mol} \%)$, and $\mathrm{Al}_{2} \mathrm{O}_{3}(12 \mathrm{~mol} \%)$ films deposited on sapphire substrates, respectively. In our previous work, $\mathrm{SiO}_{2}$ layers without $\mathrm{Al}_{2} \mathrm{O}_{3}$ were used as sacrificial layers between the $\mathrm{WO}_{3}$-based layers. ${ }^{(15)}$ In that case, the upper supporting pillars were very thin or removed after prolonged etching time. Thus, the sensor was fragile and easy to break. In this study, the dissolution rate was controlled by adding $\mathrm{Al}_{2} \mathrm{O}_{3}$ to the $\mathrm{SiO}_{2}$ film to form wide interspaces as well as thick pillars.

The active area of the sensing film was about $2.5 \times 2.5 \mathrm{~mm}^{2} .1 \mathrm{wt} \% \mathrm{Ag}$ was also doped to the $\mathrm{WO}_{3}$-based film. The electrode was $\mathrm{Pt}+\mathrm{W}(5 \mathrm{~mol} \%)$ and its thickness was $200 \mathrm{~nm}$. All the films were deposited by RF sputtering. The sputtering conditions were the same as those described in Table 1. Photolithography was used to define the sensor and electrode geometries. The films were thermally treated at $600{ }^{\circ} \mathrm{C}$ for $5 \mathrm{~h}$ in air to allow for the recovery from various defects and the stabilization of the crystal structure.

Triple-layered and double-layered sensors were also fabricated by a similar process for comparison with the quadruple-layered one in terms of the sensitivity to NO gas and the response and recovery times.

The surface morphologies of a $\mathrm{WO}_{3}$-based film after annealing at $600{ }^{\circ} \mathrm{C}$ and subsequent etching by diluted fluoric acid are shown in Figs. 3(a) and 3(b), respectively. These photographs were taken by SEM (JEOL, JSM-6010PLUS/LA). The sensing film itself was porous with granular structures of about $100 \mathrm{~nm}$ diameter before etching, while possible microscopic pores are not clearly observed. The film exhibited many pores after etching, through which the underlying $\mathrm{SiO}_{2}$-based film was dissolved. Our previous work shows pillars under the uppermost $\mathrm{WO}_{3}$-based film by using an optical microscope (Keyence, VH-Z500). ${ }^{(15)}$ As the $\mathrm{WO}_{3}$-based film was transparent, $\mathrm{SiO}_{2}$ pillars were clearly visible through the film. 


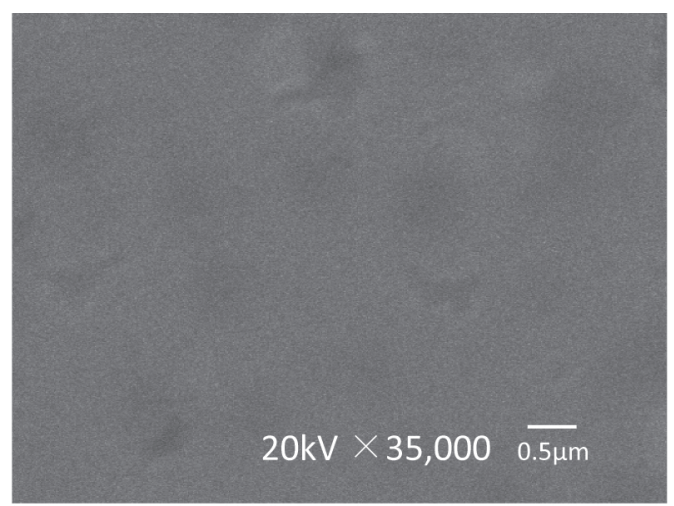

(a)

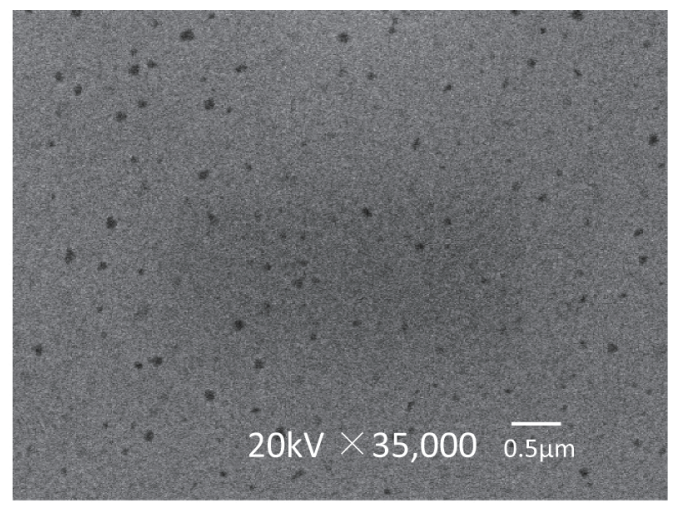

(b)

Fig. 3. SEM images of a double-layered $\mathrm{WO}_{3}$-based thin film: (a) after annealing at $600{ }^{\circ} \mathrm{C}$ and (b) after subsequent etching with diluted fluoric acid.

\section{Experimental Results and Discussion}

The sensors were tested in a closed test box (Figaro Engineering, SR-3) made of polymethylmethacrylate (PMMA). Its volume was 5.4 L. The sensors were heated to 100-400 ${ }^{\circ} \mathrm{C}$ by using a commercially available Pt heater covered with alumina. The experimental setup is shown in Fig. 4. Varous test gases were injected by a syringe. After the sensor resistance reached a steady value, the lid was opened to extract the test gases. $\mathrm{NO}, \mathrm{NO}_{2}, \mathrm{NH}_{3}$, and $\mathrm{SO}_{2}$ gases were taken from the gas cylinders (Taiyo Nippon Sanso) containing 1000 ppm NO, 200 ppm $\mathrm{NO}_{2}, 1000 \mathrm{ppm} \mathrm{NH}$, and $200 \mathrm{ppm} \mathrm{SO}$, respectively. All these gases were balanced with nitrogen. $\mathrm{CO}, \mathrm{CO}_{2}$, and $\mathrm{H}_{2}$ gases were taken from the gas cylinders (Taiyo Nippon Sanso) containing standard gases with $99.9 \%$ purity. The NO gas concentration in the test box ranged from 0.1 to $10 \mathrm{ppm}$. The ambient temperature was about $23{ }^{\circ} \mathrm{C}$ and the relative humidity ranged from 26 to $45 \%$ RH.

\subsection{Effect of Ag doping into $\mathrm{WO}_{3}$-based film for the sensors without interspaces}

The effect of $\mathrm{Ag}$ doping into the $\mathrm{WO}_{3}$-based film was studied for the sensors without interspaces. The $\mathrm{Ag}$ doping amounts were 0.5, 1, 2, and $0 \mathrm{wt} \%$ (nondoped). NO gas concentration was fixed at $5 \mathrm{ppm}$. Figure 5 shows the temperature dependence of the sensitivity of the sensors with different Ag doping amounts. Here, the sensitivity $S$ is defined as the ratio of the resistance in the gas, $R_{g}$, to that in the ambient air, $R_{a}$.

$$
S=\frac{R_{g}}{R_{a}}
$$

All the sensors doped with Ag exhibited higher sensitivity to NO gas than the nondoped sensor. The sensor doped with $1 \mathrm{wt} \% \mathrm{Ag}$ showed the highest sensitivity and its sensitivity 


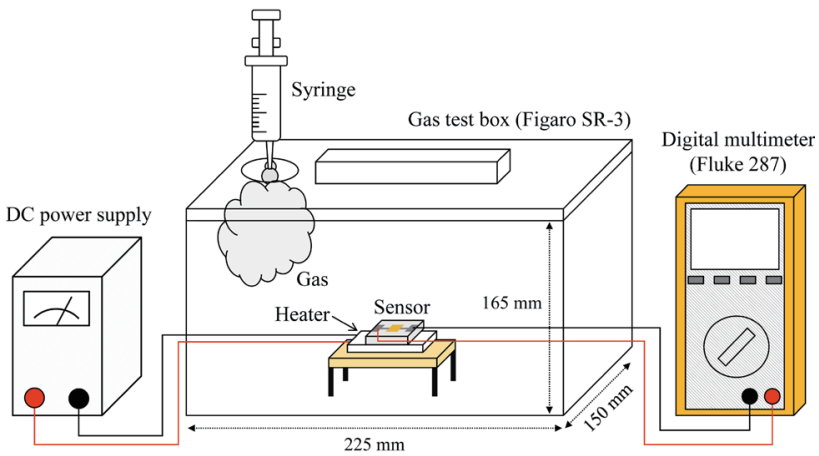

Fig. 4. (Color online) Experimental setup.

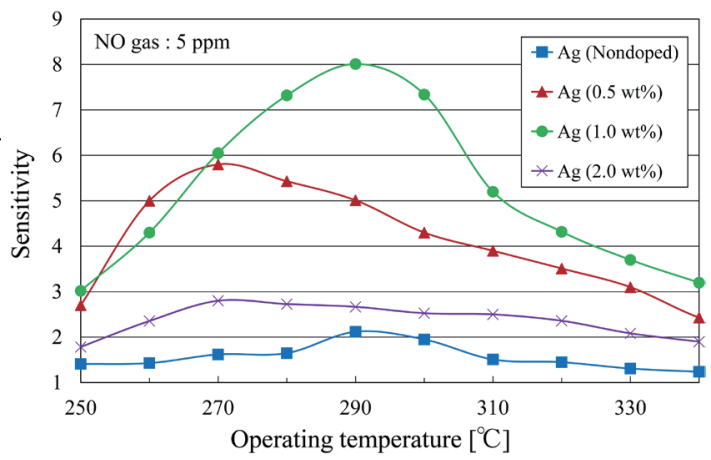

Fig. 5. (Color online) Dependence of sensitivity on operating temperature for gas sensors without interspaces with different $\mathrm{Ag}$ doping amounts into $\mathrm{WO}_{3}$.

became maximum at an operating temperature of $290{ }^{\circ} \mathrm{C}$. The experiments revealed that the doping amount of $1 \mathrm{wt} \% \mathrm{Ag}$ into the $\mathrm{WO}_{3}$ film was the best for $\mathrm{NO}$ detection.

\subsection{Effect of wet etching time of sacrificial $\mathrm{SiO}_{2}$ layers for the sensors with interspaces}

The effect of the wet etching time of sacrificial $\mathrm{SiO}_{2}$ layers for the sensors with interspaces was investigated. The double-layered, triple-layered, and quadruple-layered sensors were used in this experiment. The sensitivity to NO gas was measured at an operating temperature of 290 ${ }^{\circ} \mathrm{C}$. The NO gas concentration was $5 \mathrm{ppm}$. Figure 6 shows the dependence of the sensitivity on the wet etching time of the sacrificial $\mathrm{SiO}_{2}$ layers.

For the double-layered sensor, the maximum sensitivity to NO gas was obtained at the etching time of $7 \mathrm{~min}$, while for the quadruple-layered sensor, the maximum sensitivity was obtained at the etching time of $20 \mathrm{~min}$. The sensitivity to NO gas is higher for the quadruplelayered sensor than for the double-layered and triple-layered sensors regardless of etching time owing to the higher total surface area of the $\mathrm{WO}_{3}$-based sensing films.

\subsection{Dependence of the sensitivity on the NO concentration in air of the multilayered thin- film sensors with interspaces and that without interspaces}

Figures 7(a) and 7(b) show the dependence of the sensitivity on NO concentration for the quadruple-layered and double-layered sensors with interspaces as well as that without interspaces in the lower ( 0.1 to $1 \mathrm{ppm})$ and higher (1 to $10 \mathrm{ppm})$ concentration range, respectively. The sensitivity of the multiple-layered sensors with interspaces is higher than that of the sensor without interspaces above $1 \mathrm{ppm}$. The sensitivity of the double-layered sensor is slightly higher than that of the quadruple-layered sensor below $1 \mathrm{ppm}$. This is due to the slow response of the quadruple-layered sensor compared with that of the double-layered sensor because the NO gas diffusion into the inner sensing films takes more time for the quadruplelayered sensor. From Fig. 7(a), it was clear that the double-layered and quadruple-layered sensors can detect as low as $0.5 \mathrm{ppm} \mathrm{NO}$ gas. 


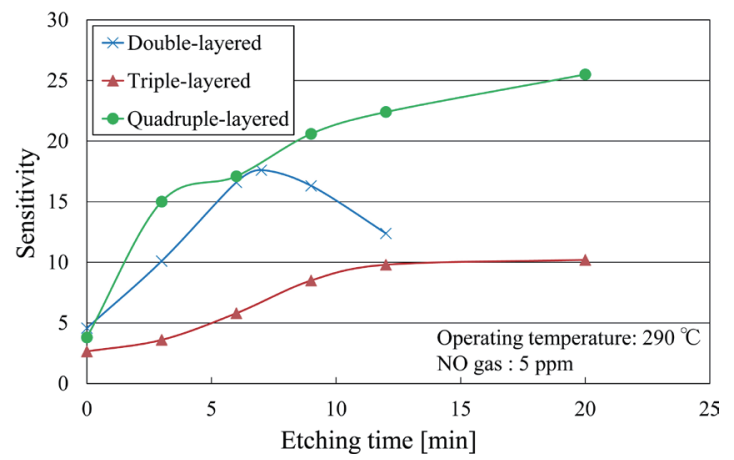

Fig. 6. (Color online) Dependence of sensitivity on etching time of sacrificial $\mathrm{SiO}_{2}$ layers of multilayered gas sensors with interspaces.

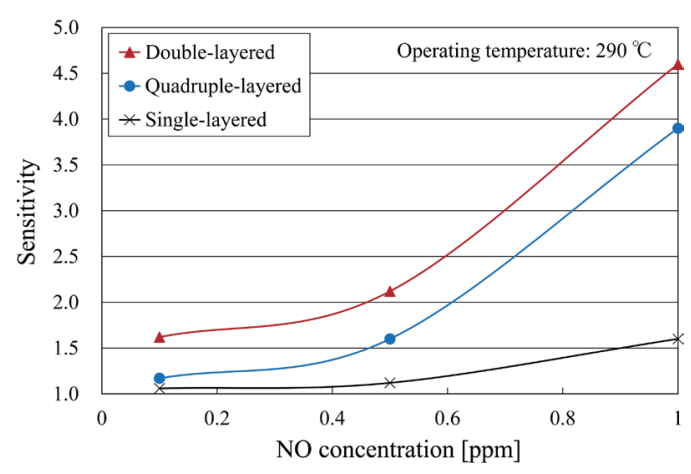

(a)

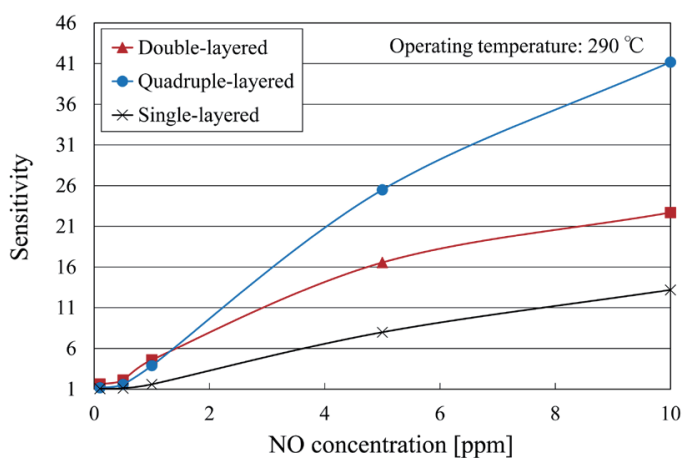

(b)

Fig. 7. (Color online) Dependence of sensitivity on NO concentration of multiple-layered gas sensors with interspaces as well as that without interspaces in (a) the lower and (b) higher NO concentration ranges.

\subsection{Response and recovery times of the multilayered sensors with interspaces}

The response and recovery times to $\mathrm{NO}$ gas were examined. Figure 8 shows the transient response toward $\mathrm{NO}$ gas for the double-layered (a) and quadruple-layered (b) gas sensors. The operating temperature was $290{ }^{\circ} \mathrm{C}$ and the gas concentration was $1 \mathrm{ppm}$. The response and recovery times were defined as the time for the resistance to reach a $90 \%$ change. The response and recovery times are 81 and $138 \mathrm{~s}$ for the double-layered sensor, while they are 244 and 599 $\mathrm{s}$ for the quadruple-layered sensor, respectively. These results revealed that the double-layered sensor had faster response and recovery characteristics, although it showed less sensitivity to $\mathrm{NO}$ gas at higher concentrations above $1 \mathrm{ppm}$. The slower response and recovery for the quadruple-layered sensor are possibly due to the slow diffusion of NO gas into and from the inner interspaces as mentioned earlier.

\subsection{Gas selectivity of the double-layered sensor with interspaces}

The sensitivity to various gases for the double-layered sensor with interspaces is shown in Fig. 9. The operating temperature was $290{ }^{\circ} \mathrm{C}$. For the $\mathrm{NH}_{3}, \mathrm{CO}, \mathrm{CO}_{2}$, and $\mathrm{H}_{2}$ gases, the sensitivity $S$ is defined as the ratio of the resistance in ambient air, $R_{a}$, to that in gas, $R_{g}$, as shown in the following, while for the other gases, it is defined as Eq. (1). 


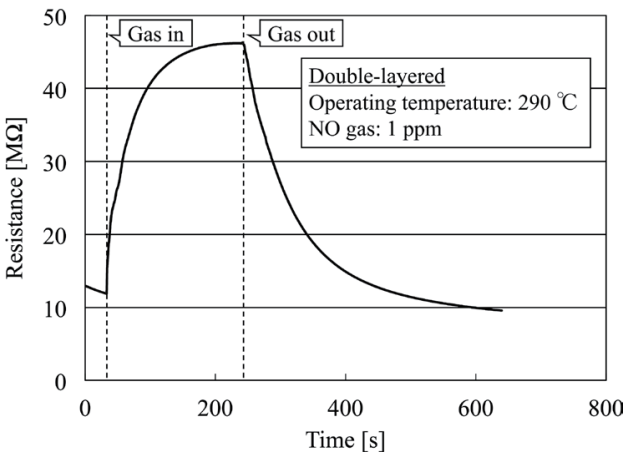

(a)

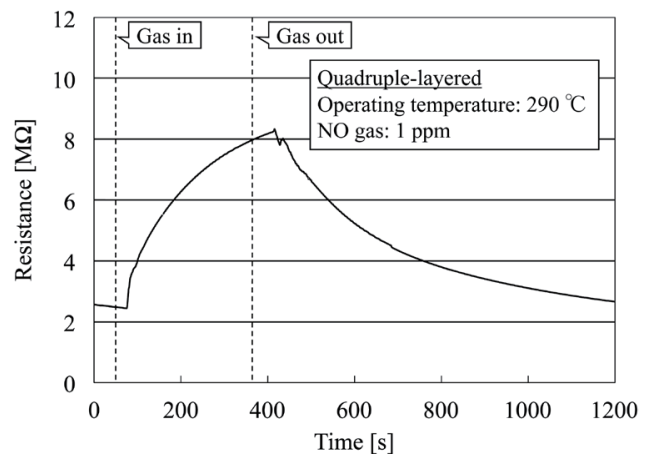

(b)

Fig. 8. Transient responses to NO of (a) double-layered and (b) quadruple-layered gas sensors with interspaces.

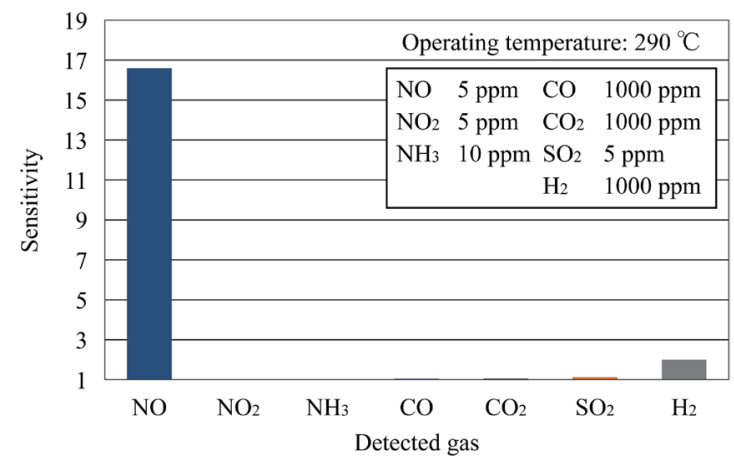

Fig. 9. (Color online) Gas selectivity of double-layered gas sensor with interspaces.

$$
S=\frac{R_{a}}{R_{g}}
$$

The sensitivity to $\mathrm{NO}_{2}, \mathrm{NH}_{3}, \mathrm{CO}, \mathrm{CO}_{2}$, and $\mathrm{SO}_{2}$ gases was very low. It was slightly higher to hydrogen. However, the sensitivity to $5 \mathrm{ppm} \mathrm{NO}$ gas was much higher than that to $1000 \mathrm{ppm}$ hydrogen. Therefore, the selectivity to NO gas was satisfactory.

\subsection{Proposed mechanism of nitric oxide gas sensing}

The mechanism of NO gas sensing is proposed and it is shown why the multilayered sensors with interspaces are sensitive and selective to NO gas. The gap between the sensing films is ca. $20 \mathrm{~nm}$, which is much shorter than the mean free path (ca. $100 \mathrm{~nm}$ ) of $\mathrm{NO}, \mathrm{O}_{2}$, and $\mathrm{N}_{2}$ gases. Thus, these gas molecules inside interspaces collide with the upper and lower sensing films many times before colliding with other molecules. Some $\mathrm{NO}$ and $\mathrm{O}_{2}$ molecules adsorb on the surface of the sensing films because they are both chemically active. When they desorb from the surface, a part of them can be activated. The activated species easily adsorb on the surface again and tend to become chemisorbed species such as $\mathrm{NO}^{-}$and $\mathrm{O}_{2}{ }^{-}$on the surface by accepting electrons from the sensing film as shown below.

$$
\mathrm{NO}+\mathrm{e}^{-} \rightarrow \mathrm{NO}^{-}
$$




$$
\mathrm{O}_{2}+\mathrm{e}^{-} \rightarrow \mathrm{O}_{2}^{-}
$$

Some $\mathrm{O}_{2}$ molecules may be chemisorbed as $\mathrm{O}^{-}$and $\mathrm{O}^{2-}$ depending on the temperature. ${ }^{(17)}$ Although the reaction such as Eq. (4) occurs on the ordinary surface of the sensing film without interspaces, the reaction is promoted by the increased number of collisions with the sensing films and thus the resultant $\mathrm{O}_{2}{ }^{-}$species increase in number for the multilayered films with interspaces. Thus, the reaction of $\mathrm{NO}$ and $\mathrm{O}_{2}{ }^{-}$species is accelerated on the surface compared with that on the ordinary surface as follows.

$$
2 \mathrm{NO}+\mathrm{O}_{2}^{-}+\mathrm{e}^{-} \rightarrow 2 \mathrm{NO}_{2}^{-}
$$

This reaction is associated with the acceptance of more electrons from the sensing film, decreasing the electron concentration of the film and thus increasing the sensor resistance. This is possibly the reason why the sensitivity to NO is high for the multilayered sensor with interspaces.

Ag doping into $\mathrm{WO}_{3}$ has been reported to be effective in increasing the sensitivity to NO. ${ }^{(13,14)}$ However, the microscopic structures of the sensing materials are different from that in this study. In this study, $\mathrm{Ag}$ atoms on the sensing surface promote $\mathrm{O}_{2}$ adsorption and hence chemisorbed species such as $\mathrm{O}_{2}{ }^{-}$increase in number as a result of the reaction shown in Eq. (4). Thus, Ag doping into the $\mathrm{WO}_{3}$-based film successfully enhances the sensitivity to NO. Figure 10 illustrates the proposed model of NO gas sensing. NO gas reacts with chemisorbed oxygen species on the surface of $\mathrm{Ag}$ atoms on the $\mathrm{WO}_{3}$-based film, accepting electrons from the film as shown in Eq. (5). Ag is also doped inside the $\mathrm{WO}_{3}$ film. However, the $\mathrm{Ag}$ atoms that appear on the surface are active, enhancing the chemisorption of oxygen atoms.

$\mathrm{NO}_{2}, \mathrm{SO}_{2}$, and $\mathrm{CO}_{2}$ do not react with chemisorbed oxygen species. This may be the reason why the sensors do not exhibit high sensitivity to these gases. $\mathrm{CO}$ and $\mathrm{H}_{2}$ react with chemisorbed oxygen species; the sensors show a slight sensitivity to these gases. However, the reaction rates of $\mathrm{CO}$ and $\mathrm{H}_{2}$ are not much higher than that of $\mathrm{NO}$, which is a type of radical and chemically active. Therefore, the sensors are sensitive and selective to NO gas.

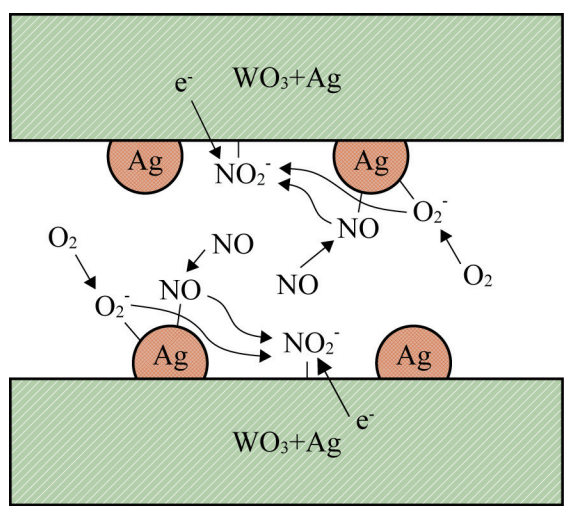

Fig. 10. (Color online) Proposed mechanism of NO gas sensing. 


\section{Conclusions}

Novel $\mathrm{NO}$ gas sensors were developed using multilayered $\mathrm{WO}_{3}$-based thin films with interspaces. Ag doping into the $\mathrm{WO}_{3}$ thin film was effective in increasing the sensitivity to NO. A multilayered thin film with interspaces successfully enhanced both sensitivity and selectivity to NO. The developed sensor with quadruple-sensing layers can detect as low as $0.5 \mathrm{ppm}$ NO gas with good selectivity at an operating temperature of $290{ }^{\circ} \mathrm{C}$. A model was proposed to explain the sensing mechanism of $\mathrm{NO}$ gas. The response and recovery times were 81 and $138 \mathrm{~s}$, respectively, for the double-layered sensor, while its sensitivity was lower than that of the quadruple-layered sensor. The sensors are thus promising as a portable and inexpensive NO sensing device in various application fields such as environmental monitoring and health diagnosis.

An even higher sensitivity is required to determine the NO gas concentration contained in exhaled breath. The device configurations, materials, and additives have to be optimized in future work.

\section{References}

1 B. T. Marquis and J. F. Vetelino: Sens. Actuators, B 77 (2001) 100

2 G. Ko, H. Y. Kim, J. Ahn, Y. M. Park, K. Y. Lee, and J. Kim: Curr. Appl. Phys. 10 (2010) 1002.

3 N. Miura, H. Kurosawa, M. Hasei, G. Lu, and N. Yamazoe: Solid State Ionics 86 (1996) 1069.

4 N. F. Szabo and P. K. Dutta: Solid State Ionics 171 (2004) 183.

5 A. Dutta, N. Kaabbuathong, M. L. Grilli, E. Di Bartolomeo, and E. Traversa: J. Electrochem. Soc. 150 (2003) H33.

6 J. Yoo, S. Chatterjee, and E. D. Wachsman: Sens. Actuators, B 122 (2007) 644.

7 E. Di Bartolomeo, N. Kaabbuathong, M. L. Grilli, and E. Traversa: Solid State Ionics 171 (2004) 173.

8 N. Yamazoe and N. Miura: New Approaches in the Design of Gas Sensors: Gas Sensor (Kluwer, Dordrecht, 1992) p. 1.

9 S. C. Moulzolf, S. Ding, and R. J. Lad: Sens. Actuators, B 77 (2001) 375.

10 X. Wang, N. Miura, and N. Yamazoe: Sens. Actuators, B 66 (2000) 74.

11 M. Akiyama, J. Tamaki, N. Miura, and N. Yamazoe: Chem. Lett. 20 (1991) 1611.

12 Z. Cai, H. Li, X. Yang, and X. Guo: Sens. Actuators, B 219 (2015) 346.

13 L. Chen and S. C. Tsang: Sens. Actuators, B 89 (2003) 68.

14 D. Chen, L. Yin, L. Ge, B. Fan, R. Zhang, J. Sun, and G. Shao: Sens. Actuators, B 185 (2013) 445

15 K. Sawaide, T. Yamada, and K. Hara: Proc. 14th IMCS (2012) 546.

16 T. Hiwatari and K. Hara: IEEJ Trans. 118-E (1998) 136.

17 G. Heiland and D. Kohl: Chemical Sensor Technology Vol. 1 (Kodansha Ltd., Tokyo and Elsevier, Amsterdam, 1988) p. 15. 